\title{
Plant Mobile Small RNAs
}

\author{
Patrice Dunoyer, ${ }^{1}$ Charles Melnyk, ${ }^{2}$ Attila Molnar, ${ }^{3}$ and R. Keith Slotkin ${ }^{4}$ \\ ${ }^{1}$ IBMP-CNRS, 67084 Strasbourg Cedex, France; ${ }^{2}$ The Sainsbury Laboratory, University of Cambridge, Cambridge CB2 1LR, \\ United Kingdom; ${ }^{3}$ Department of Plant Sciences, University of Cambridge, Cambridge CB2 3EA, United Kingdom; \\ ${ }^{4}$ Department of Molecular Genetics and Center for RNA Biology, The Ohio State University, Columbus, Ohio 43210 \\ Correspondence: patrice.dunoyer@ibmp-cnrs.unistra.fr
}

In plants, RNA silencing is a fundamental regulator of gene expression, heterochromatin formation, suppression of transposable elements, and defense against viruses. The sequence specificity of these processes relies on small noncoding RNA (sRNA) molecules. Although the spreading of RNA silencing across the plant has been recognized for nearly two decades, only recently have sRNAs been formally demonstrated as the mobile silencing signals. Here, we discuss the various types of mobile sRNA molecules, their short- and long-range movement, and their function in recipient cells.

RNA silencing is a regulatory mechanism that controls the expression of endogenous genes and exogenous molecular parasites such as viruses, transgenes, and transposable elements. One of the most fascinating aspects of RNA silencing found in plants and invertebrates is its mobile nature-in other words, its ability to spread from the cell where it has been initiated to neighboring cells. This phenomenon relies on the movement of small noncoding RNA molecules (sRNA, 21-24 nucleotides [nt] in length) that provide the sequence specificity of the silencing effects. In plants, there are two major classes of sRNAs: short interfering RNAs (siRNAs) and micro RNAs (miRNAs). These sRNAs are generated by diverse and sometimes interacting biochemical pathways, which may influence their mobility. Movement of plant sRNAs falls into two main categories: cell-to-cell (short-range) and systemic (long-range) movement (Melnyk et al. 2011).

\section{LONG-RANGE MOVEMENT OF SMALL RNA}

The first hint of the mobile nature of RNA silencing in plants was provided by studies of tobacco exhibiting localized transgene silencing that was transmitted to new growth, following a pattern of vascular transport (see Fig. 1). The existence of a signaling molecule for RNA silencing was later confirmed by elegant plant grafting experiments (Melnyk et al. 2011). These studies demonstrated that a silencing signal emitted from the silenced transgenic rootstock travelled over long distances through the vasculature and could trigger de novo silencing of a homologous transgene in distant tissues of the plant. However, the identification of the systemic silencing signal took several years and was only recently conclusively addressed with the rise of high-throughput sequencing coupled to Arabidopsis micrografting experiments (Dunoyer et al. 2010a; Molnar et al. 2010). Detection of both transgenic and endogenous siRNAs in Dicer triple mutant grafted tissues (which are defective for siRNA biogenesis) provided strong support that siRNAs, as opposed to their precursor transcripts, are the mobile long-distance silencing signal. These experiments also demonstrated that mobile siRNAs are able to direct de novo methylation at target loci over long distances through a process of RNA-directed DNA methylation (Dunoyer et al. 2010a; Molnar et al. 2010). Intriguingly, only one third of the endogenous Arabidopsis siRNA loci generate mobile siRNAs, suggesting a complex channeling process that underlies mobility.

\section{SHORT-DISTANCE CELL-TO-CELL MOVEMENT}

Upon local induction, RNA silencing spreads from the site of initiation to the surrounding 10 to 15 neighboring cells (see Fig. 1). This cell-to-cell movement likely occurs through plasmodesmata (the pores interconnecting plant

Editors: C. David Allis, Marie-Laure Caparros, Thomas Jenuwein, and Danny Reinberg

Additional Perspectives on Epigenetics available at www.cshperspectives.org

Copyright $(C 2013$ Cold Spring Harbor Laboratory Press; all rights reserved; doi: 10.1101/cshperspect.a017897

Cite this article as Cold Spring Harb Perspect Biol 2013;5:a017897 
A Cell-to-cell movement through plasmodesmata

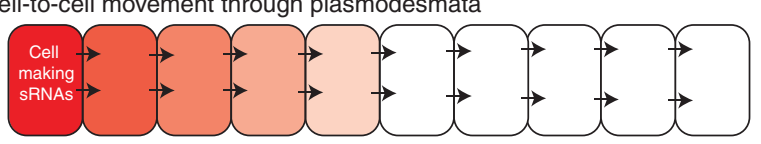

B Cell-to-cell movement through plasmodesmata and reiterated by RNAi

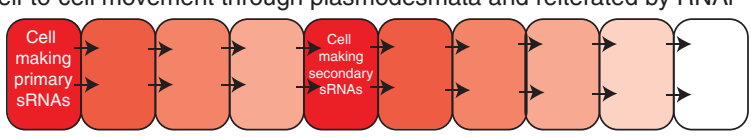

C Long-range movement through the vasculature

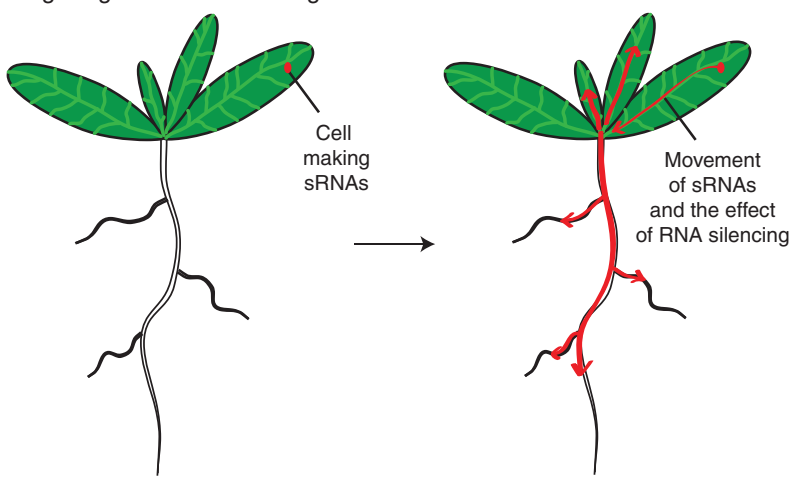

D Critical experiment that defined sRNA long-range movement

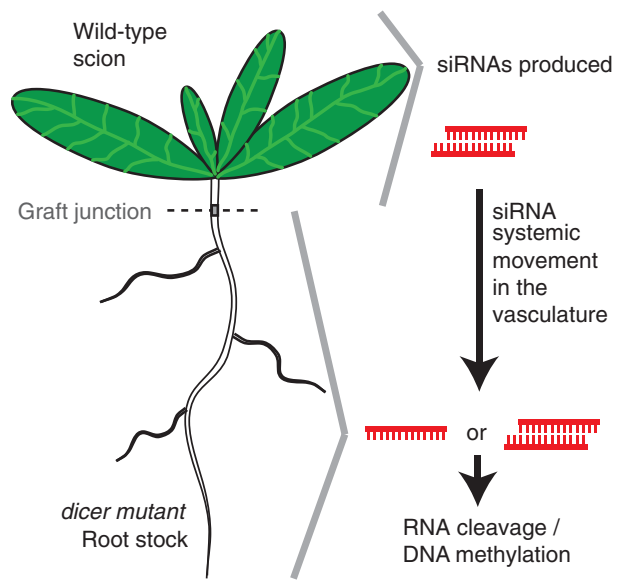

Figure 1. The movement of plant sRNAs, and therefore RNA silencing, can occur through two distinct mechanisms. (A) sRNAs can move through channels between plant cells called plasmodesmata. The diffusion of sRNAs from the cell in which they were made is seen in the red gradient. (B) Cell-to-cell movement can be extended beyond the range of diffusion through plasmodesmata by recipient cells using the primary sRNAs to initiate successive rounds of RNAi and produce secondary sRNAs. This amplification process is called transitivity. (C) Long-range movement from one organ to another is accomplished by loading the plant vascular system with sRNAs. Cells producing sRNAs and the movement of sRNAs are depicted in red. (D) In this critical experiment that defined sRNAs as the mobile factor in RNA silencing, a wild-type top of plant (scion) was grafted to a dicer mutant root, which is incapable of producing siRNAs. SiRNAs generated in the scion were transported into the root where they were identified by deep sequencing, and where they functioned in RNA cleavage and RNA-directed DNA methylation. cells), as cells without plasmodesmata are resistant to mobile silencing signals. Occasionally, RNA silencing can be amplified through conversion of target RNAs into new double-stranded RNA (dsRNA) by the RNA-dependent RNA polymerase RDR6 and the production of secondary siRNAs (Melnyk et al. 2011). This amplification process, known as "transitivity" (see Fig. 1), results in a more extensive cell-to-cell spread of silencing through reiterated short-distance signaling events. Specific genetic screens were designed to identify the proteins required for biogenesis, movement, or perception of the cell-to-cell silencing signal (Melnyk et al. 2011). In these systems, Dicerlike4 (DCL4) was identified for this short-range silencing movement, suggesting a key role for DCL4-generated 21-nt siRNAs. Subsequently, these 21-nt siRNAs were directly identified as the cell-to-cell silencing signal by using a combination of transgenic reporter systems, viral suppressors of RNA silencing that specifically sequester 21-nt siRNAs, and the exogenous application (bombardment) of fluorescently labeled 21-nt siRNAs (Dunoyer et al. 2010b). In addition to DCL4, several mutations in the RNA-directed DNA methylation pathway compromised cell-to-cell silencing movement, but this mechanism remains ill defined. Of note, bombardment with RNA-directed DNA methylation pathway-associated 24-nt siRNAs moved to a similar extent as the 21-nt siRNAs, indicating that both size classes are mobile (Dunoyer et al. 2010a, 2010b).

\section{FUNCTIONS OF SMALL RNA MOVEMENT}

\section{Developmental Patterning}

Mobile small RNAs in plants are generated through several pathways from either endogenous or exogenous sources. During wild-type development, sRNA movement establishes gradients of target mRNA concentrations used in specifying developmental patterns. For example, movement of endogenous 21-nt siRNAs from the top of the leaves, where they are produced, to the bottom cell layers, generates a gradient that functions in the establishment of top-tobottom leaf pattern formation (Melnyk et al. 2011). Certain micro RNAs (miRNAs) are also mobile. For instance, miR165/166 is produced in specific root cells and moves to adjacent cells, where it targets mRNAs encoding multiple transcription factors. The resulting gradient of target mRNA determines vascular cell types (Melnyk et al. 2011). Interestingly, some miRNAs are also thought to move long distances in plants. Upon phosphate starvation, one miRNA is translocated from the top of the plant to the root, where it degrades its target mRNA that encodes a suppressor of phosphate uptake (Melnyk et al. 2011). 


\section{Viral Resistance}

Because viruses are potent triggers of RNA silencing in infected cells, they also represent huge sources of mobile small RNAs. These virus-derived siRNAs can move both cell-tocell and systemically ahead of the infection front and prime the antiviral silencing response in naïve cells that are yet to be infected. This effect was shown using a movement-deficient virus carrying a fragment of an endogenous gene. Although this virus remained restricted to the infected lower leaves, it triggered silencing of the endogenous gene in and around the vasculature in distant parts of the plant. In addition, viral suppressors of RNA silencing that specifically sequester siRNAs are required for the successful infection of neighboring cells (Dunoyer et al. 2010b; Melnyk et al. 2011).

\section{Epigenetic Changes}

Work with viruses suggests that mobile silencing signals could direct epigenetic changes. Upon infection with an RNAvirus, silencing can be established on a separate stably transformed nonviral homologous transgene. This silencing is manifested as DNA methylation at the transgene promoter and is inherited to subsequent generations in the absence of the virus, demonstrating heritable epigenetic silencing (Melnyk et al. 2011). Heritable epigenetic silencing is also known to occur at endogenous transposable elements (TEs). In Arabidopsis, TEs activate in the cells that neighbor the sperm cells and the embryo, becoming a source of siRNAs (Slotkin et al. 2009). The activation of TEs in these cells coincides with a corresponding increase in DNA methylation in the sperm cells and embryo, suggesting that the TE siRNAs may move into the neighboring gametes and subsequent embryo and reinforce RNA-directed DNA methylation and trans-generational TE silencing (Slotkin et al. 2009). However, the direct movement of endogenous TE siRNAs into gametes or the embryo has not been demonstrated.

\section{MOVEMENT OF PLANT SMALL RNAS TO OTHER ORGANISMS}

One interesting observation is the ability of mobile silencing signals to move outside of plants. RNA silencing transgenes expressed in a plant can silence complementary genes in fungal and invertebrate pathogens that feed on the plant (Melnyk et al. 2011). Transgenic RNA silencing signals can also pass between several plants through a parasitic plant intermediate (Melnyk et al. 2011). These examples represent important biotechnological applications for mobile RNA silencing and hint that similar sRNA movement may occur in nature from the plant to pathogens or symbionts.

\section{REFERENCES}

Dunoyer P, Brosnan CA, Schott G, Wang Y, Jay F, Alioua A, Himber C, Voinnet O. 2010a. An endogenous, systemic RNAi pathway in plants. EMBO J 29: 1699-1712.

Dunoyer P, Schott G, Himber C, Meyer D, Takeda A, Carrington JC, Voinnet O. 2010b. Small RNA duplexes function as mobile silencing signals between plant cells. Science 328: 912-916.

Melnyk CW, Molnar A, Baulcombe DC. 2011. Intercellular and systemic movement of RNA silencing. EMBO J 30: 3553-3563.

Molnar A, Melnyk CW, Bassett A, Hardcastle TJ, Dunn R, Baulcombe DC. 2010. Small silencing RNAs in plants are mobile and direct epigenetic modification in recipient cells. Science 328: 872-875.

Slotkin RK, Vaughn M, Borges F, Tanurdzić M, Becker JD, Feijó JA Martienssen RA. 2009. Epigenetic reprogramming and small RNA silencing of transposable elements in pollen. Cell 136: 461-472. 


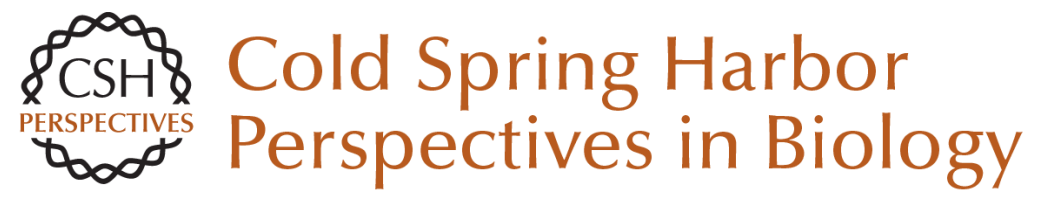

\section{Plant Mobile Small RNAs}

Patrice Dunoyer, Charles Melnyk, Attila Molnar and R. Keith Slotkin

Cold Spring Harb Perspect Biol 2013; doi: 10.1101/cshperspect.a017897

Subject Collection Epigenetics

Metabolic Signaling to Chromatin Shelley L. Berger and Paolo Sassone-Corsi

Histone and DNA Modifications as Regulators of Neuronal Development and Function Stavros Lomvardas and Tom Maniatis

Histone Modifications and Cancer James E. Audia and Robert M. Campbell

Epigenetics and Human Disease Huda Y. Zoghbi and Arthur L. Beaudet

Induced Pluripotency and Epigenetic Reprogramming Konrad Hochedlinger and Rudolf Jaenisch

Long-Range Chromatin Interactions Job Dekker and Tom Misteli

RNAi and Heterochromatin Assembly Robert Martienssen and Danesh Moazed

Dosage Compensation in Drosophila John C. Lucchesi and Mitzi I. Kuroda
Epigenetic Determinants of Cancer Stephen B. Baylin and Peter A. Jones

Maintenance of Epigenetic Information Geneviève Almouzni and Howard Cedar

A Structural Perspective on Readout of Epigenetic Histone and DNA Methylation Marks Dinshaw J. Patel

The Necessity of Chromatin: A View in

Perspective Vincenzo Pirrotta

Germline and Pluripotent Stem Cells Wolf Reik and M. Azim Surani

Comprehensive Catalog of Currently Documented Histone Modifications Yingming Zhao and Benjamin A. Garcia

Epigenetic Regulation of Chromatin States in Schizosaccharomyces pombe Robin C. Allshire and Karl Ekwall

Histone Variants and Epigenetics Steven Henikoff and M. Mitchell Smith

For additional articles in this collection, see http://cshperspectives.cshlp.org/cgi/collection/

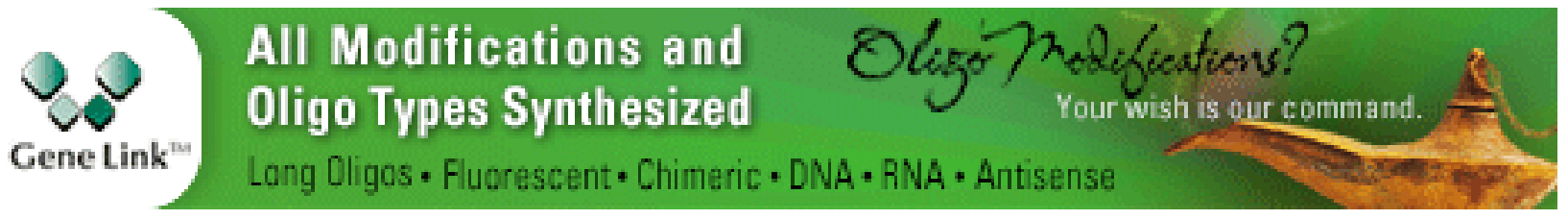

Copyright @ 2013 Cold Spring Harbor Laboratory Press; all rights reserved 
For additional articles in this collection, see http://cshperspectives.cshlp.org/cgi/collection/

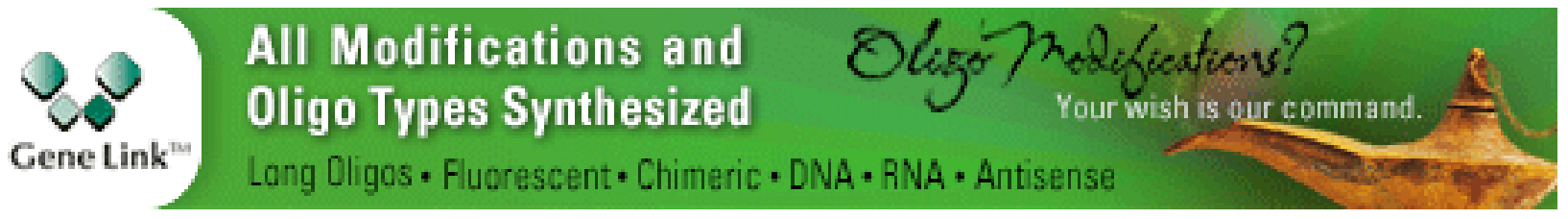

Copyright @ 2013 Cold Spring Harbor Laboratory Press; all rights reserved 